\title{
Identification and Expression Profiling of the Auxin Response Factors in Dendrobium officinale under Abiotic Stresses
}

\author{
Zhehao Chen ${ }^{1}$, Ye Yuan ${ }^{1}$, Di Fu ${ }^{1}$, Chenjia Shen ${ }^{1,2}$ and Yanjun Yang ${ }^{1,2, *}$ \\ 1 College of Life and Environmental Sciences, Hangzhou Normal University, Hangzhou 310036, China; \\ zhchen@hznu.edu.cn (Z.C.); y_yuan1130@126.com (Y.Y.); fudiclh@163.com (D.F.); shencj@hznu.edu.cn (C.S.) \\ 2 Zhejiang Provincial Key Laboratory for Genetic Improvement and Quality Control of Medicinal Plants, \\ Hangzhou Normal University, Hangzhou 310036, China \\ * Correspondence: yjyang@hznu.edu.cn; Tel.: +86-571-2886-7258
}

Academic Editor: Jianhua Zhu

Received: 14 March 2017; Accepted: 25 April 2017; Published: 4 May 2017

\begin{abstract}
Auxin response factor (ARF) proteins play roles in plant responses to diverse environmental stresses by binding specifically to the auxin response element in the promoters of target genes. Using our latest public Dendrobium transcriptomes, a comprehensive characterization and analysis of 14 DnARF genes were performed. Three selected DnARFs, including DnARF1, DnARF4, and DnARF6, were confirmed to be nuclear proteins according to their transient expression in epidermal cells of Nicotiana benthamiana leaves. Furthermore, the transcription activation abilities of DnARF1, DnARF4, and DnARF6 were tested in a yeast system. Our data showed that DnARF6 is a transcriptional activator in Dendrobium officinale. To uncover the basic information of DnARF gene responses to abiotic stresses, we analyzed their expression patterns under various hormones and abiotic treatments. Based on our data, several hormones and significant stress responsive DnARF genes have been identified. Since auxin and $A R F$ genes have been identified in many plant species, our data is imperative to reveal the function of $A R F$ mediated auxin signaling in the adaptation to the challenging Dendrobium environment.
\end{abstract}

Keywords: abiotic stress; auxin; ARF; Dendrobium officinale; transcriptional activator

\section{Introduction}

Phytohormones play pivotal roles in the various aspects of plant growth and development, including embryogenesis, organogenesis, root architecture, flower and fruit development, tissue and organ patterning, vascular development, and secondary metabolism [1-4]. In plants, auxin signaling is transmitted by transcriptional regulation of some auxin early responsive gene families, such as Auxin/Indole-3-acetic acid (Aux/IAA), Gretchen Hagen3 (GH3) and Small Auxin Up RNA (SAUR) [5]. Auxin response factor (ARF) proteins, an essential component of the auxin signaling pathway, regulate the expression levels of auxin response genes by targeting the auxin response elements (AuxREs) on their promoters [6]. A typical ARF protein consists of three conserved domains: a plant specific B3-like DNA-binding domain (DBD) at the N-terminus, an activation domain (AD) or repression domain (RD) in the middle region, and a conserved C-terminal dimerization domain (CTD) [7].

In the past years, several $A R F$ gene mutants were screened to investigate the genes' genetic functions. In Arabidopsis, an ARF2 loss-of-function mutant shows severe leaf senescence and floral organ abscission [8]. Another mutant, AtARF3, displays deviant floral meristem and reproductive organs [9]. The abnormal formation of vascular strands and the embryo axis are observed in the mutant AtARF5 [10]. A mutation in the AtARF7 gene blocks the hypocotyl response to blue light 
and auxin stimuli, and shows differential growth in aerial tissues [11]. A T-DNA insertion mutant in ATARF8 was reported to control reproductive organ development by uncoupling fertilization and pollination from fruit development [12]. Furthermore, studies of double mutants of the AtARF genes provide insight into their overlapping functions. The AtARF2 gene regulates leaf senescence and floral organ abscission independently of the ethylene and cytokinin response pathways, and the AtARF1/ATARF2 double mutant enhanced many AtARF2 phenotypes [13]. The AtARF6/AtARF8 double mutant flowers are presented as infertile closed buds with short petals, short stamen filaments, undehiscent anthers and immature gynoecia, indicating that the AtARF6 and AtARF8 gene dosage quantitatively affects the timing of flower maturation [14]. Another double mutant, AtARF7/AtARF19, has a strong auxin-related phenotype, resulting in severely impaired lateral root formation and abnormal gravitropism in both hypocotyls and roots [15]. This suggests that AtARF7 and AtARF19 play essential roles in auxin mediated plant development by regulating both unique and partially overlapping sets of target genes [16]. The genome-wide identification and expression analysis of $A R F$ genes in tomato also indicated that $A R F$ genes may play diverse roles during the reproductive developmental stages in Solanaceae in general [17].

Recent studies have uncovered the involvement of $A R F S$ in responses to environmental stress. In rice, OsARF16 is required for iron and phosphate starvation responses [18,19]. Another ARF, OsARF12, is also involved in phosphate homeostasis. Expression profiling using qRT-PCR and microarray data revealed many water stress-responsive ARF genes in soybeans [20]. In tea plants, the expression of several CSARFs significantly changed under salt and dehydration stresses [21]. Expression responses of ARFs to abiotic stress also has been identified in banana [22].

Dendrobium, the second largest genus in the Orchidaceae, consists of more than 1000 species with high ornamental and medicinal values [23,24]. Stems of some Dendrobium species, such as Dendrobium officinale, contain compounds that exhibit antioxidant and antitumor activities, resulting in their high commercial values as traditional medicines $[25,26]$. Both the transcriptome and genome of $D$. officinale have been sequenced, allowing for the isolation and identification of auxin-related genes [27]. Since first cloned from Arabidopsis (AtARF1), 22 members in tomato (Solanum lycopersicon), 31 members in maize (Zea mays L.), 15 members in cucumber (Cucumis sativus), 39 members in poplar (Populus trichocarpa), 25 members in rice (Oryza sativa L.), 24 members in Medicago (Medicago truncatula), 19 members in sweet orange (Citrus sinensis), and 51 members in soybean (Glycine max L.) have already been identified $[6,17,18,28-32]$. In our study, we identified 14 ARF family genes in D. officinale, and analyzed their expression patterns under different hormones and abiotic stresses. Because auxin and $A R F$ genes have been identified in many plant species, it is important to reveal the functions of ARF mediated auxin signaling in Dendrobium's adaptation to challenging environments.

\section{Results}

\subsection{Isolation of 14 DnARF Genes from the D. officinale Plants}

Based on our previous transcriptome data, more than 30 candidate ARF genes were identified in the D. officinale plants [27]. The sequences that shared a high open reading frame (ORF) identity ( $>99 \%$ ) with other candidate DnARF genes were excluded from our study (data not shown). In total, $14 D n A R F$ genes with full-length ORFs were identified and named according to the nomenclature. The information for these DnARF genes, such as Unigene IDs, gene names, MR locations, ORF lengths, and parameters for the deduced polypeptides, are listed in Table 1. The sizes of the deduced DnARF proteins varied markedly from 522 amino acids (DnARF17) to 981 amino acids (DnARF19b). The corresponding molecular masses varied from $57.58 \mathrm{kDa}$ to $109.66 \mathrm{kDa}$, and the predicted isoelectric points varied from 5.08 (DnARF19b) to 8.40 (DnARF17). 
Table 1. The ARF family in Dendrobium officinale.

\begin{tabular}{ccccccc}
\hline \multirow{2}{*}{ Gene } & Locus ID & ORF (bp) & MR Locations & \multicolumn{2}{c}{ Deduced Polypeptide } \\
\cline { 5 - 7 } & & & & Length (aa) & Mol wt (Da) & pI \\
\hline DnARF1 & comp169620_c0_seq10 & 2016 & $358-539$ & 672 & $74,848.32$ & 5.93 \\
DnARF2a & comp173652_c0_seq13 & 2529 & $387-709$ & 843 & $93,698.06$ & 6.84 \\
DnARF2b & comp164610_c0_seq15 & 1998 & $203-536$ & 666 & $75,067.37$ & 8.13 \\
DnARF3 & comp168166_c0_seq7 & 2124 & $380-628$ & 708 & $77,816.9$ & 6.49 \\
DnARF4 & comp163222_c1_seq4 & 2103 & $373-$ end & 701 & $77,883.19$ & 6.97 \\
DnARF6 & comp171031_c0_seq23 & 2340 & $361-711$ & 780 & $87,556.94$ & 6.39 \\
DnARF7 & comp173511_c0_seq20 & 2589 & $275-756$ & 863 & $97,659.3$ & 6.71 \\
DnARF10 & comp160144_c2_seq3 & 1914 & $383-572$ & 638 & $71,309.5$ & 6.74 \\
DnARF11 & comp170249_c2_seq3 & 1755 & $307-524$ & 585 & $65,625.36$ & 6.91 \\
DnARF16a & comp165418_c0_seq20 & 1995 & $387-599$ & 665 & $73,640.69$ & 7.54 \\
DnARF16b & comp160625_c0_seq3 & 2103 & $401-612$ & 701 & $77,632.32$ & 7.83 \\
DnARF17 & comp134032_c0_seq1 & 1566 & $349-$ end & 522 & $57,580.99$ & 8.40 \\
DnARF19a & comp163679_c1_seq3 & 1875 & $381-$ end & 625 & $70,303.81$ & 8.09 \\
DnARF19b & comp150031_c0_seq2 & 2943 & $360-78$ & 981 & $109,549.1$ & 5.08 \\
\hline \multicolumn{3}{c}{ ORF: open reading frame; MR: middle region; Mol wt: molecular weight; pI: isoelectric point. }
\end{tabular}

\subsection{Isolation of 14 DnARF Genes from the D. officinale Plants}

A phylogenetic tree was built to explore the evolutionary relationship of ARFs between D. officinale and Arabidopsis. The phylogenetic distribution revealed that ARF proteins can be grouped into six subgroups, I, II, III, IV, V, and VI (Figure 1). The 14 DnARFs were not evenly distributed among the six different subgroups, and the subgroups V and VI were AtARF specific subgroups. The deduced polypeptides of the 14 DnARFs were used in a multiple sequence alignment, and their similarities were shown in Figure 2. Most of the DnARF proteins contained three conserved domains, DBD, ARF and CTD. There is a variable MR between the ARF and CTD. The results were consistent with the multiple alignments. Furthermore, two typical putative nuclear localization signals (NLS) were detected in all of the DnARF proteins: a short lysine/arginine amino acid sequence with a bipartite NLS structure was located between domains I and II, and a monopartite NLS of simian virus 40, which contains two stretches of lysine/arginine residues, was located at the end of domain II (Figure 2). The domains were next analyzed on the MEME website. Ten conserved motifs were identified and mapped to the DnARF protein sequences (Figure 3a). Motifs II, III, and IIV corresponded to the DBD; Motifs I and V corresponded to the ARF domain; and Motifs XIII and IX corresponded to the CTD. Of the 14 identified DnARFs, only DnARF4, 17 and 19a lacked the CTD. In addition, DBD was missing from two DnARFs, including DnARF2b and 7. All DnARFs contained a conserved ARF domain. Moreover, identical and conversed amino acid residues were indicated by different colorized shading (Figure 3b). 


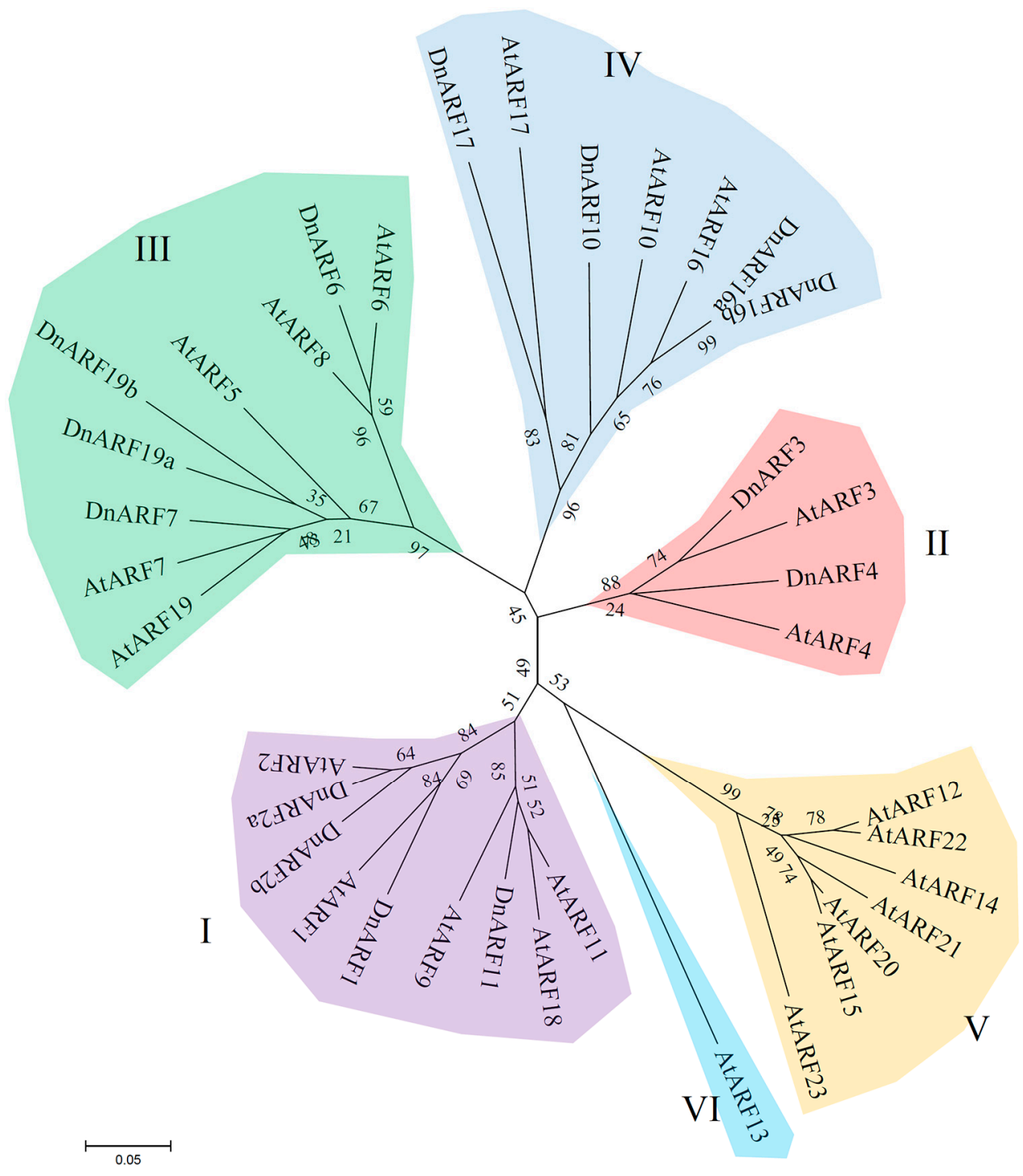

Figure 1. Phylogenetic relationships of Arabidopsis and D. officinale ARF proteins. An unrooted phylogenetic tree was constructed using MEGA 5.1 (The Biodesign Institute, Tempe, AZ, USA) by N-J method. Bootstrap values are presented for all branches. All ARF family genes were grouped into six subgroups named from I to VI. Different subfamilies were showed by different colorized shading. 


\section{DBD}
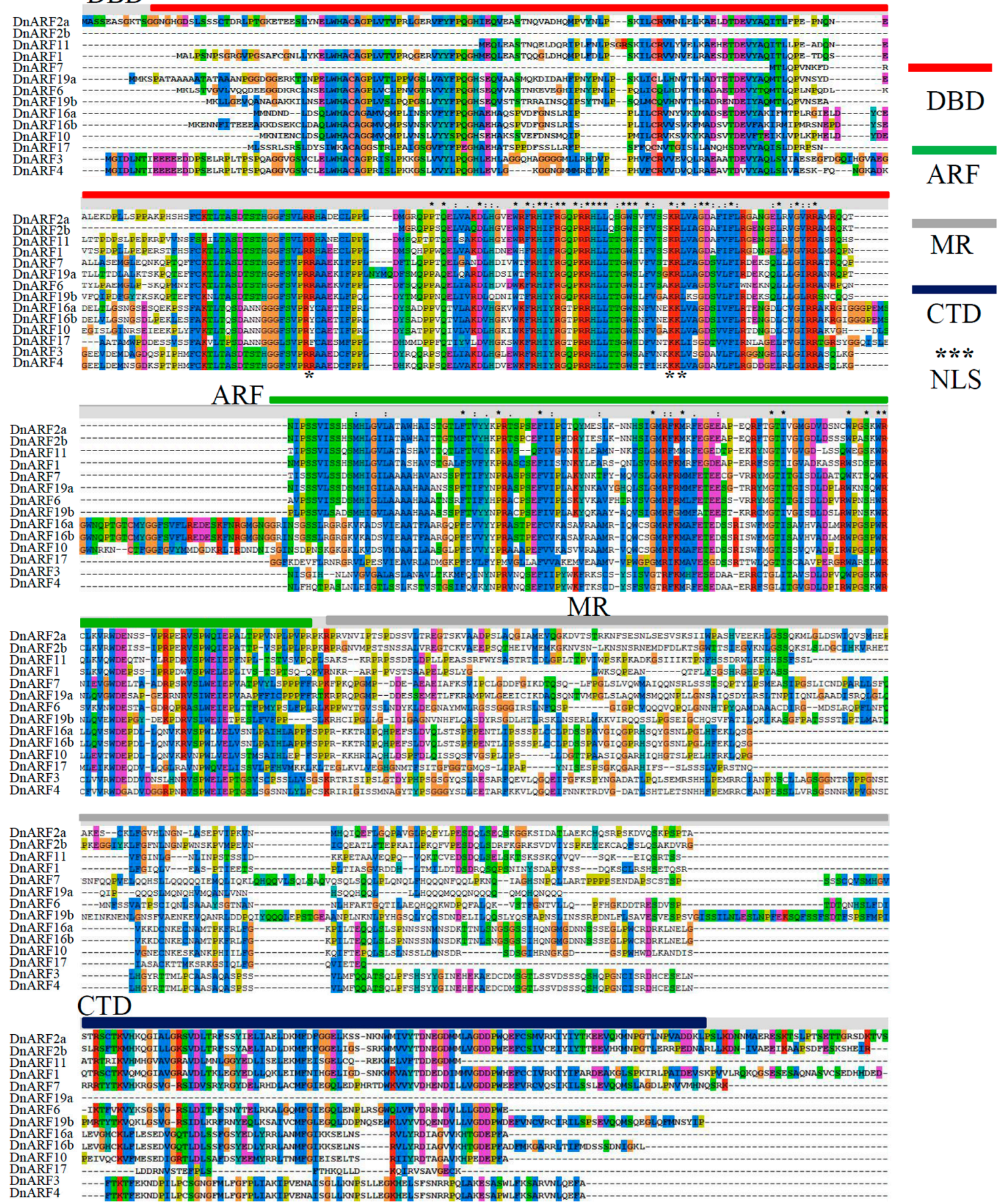

Figure 2. Protein sequences alignment and domain analysis of DnARF family proteins. Alignment of DnARF proteins obtained with the ClustalW program under default parameters. Multiple alignments of the domains DBD, ARF, MR, and CTD of the DnARF proteins were showed by different color lines. DBD: B3 DNA-binding domain; ARF: AUX_RESP domain; MR: middle region; CTD: C-terminal dimerization domain; NLS: nuclear localization signals. Colorized shading indicates identical and conversed amino acid residues, respectively. Two NLSs were marked by black asterisks. 


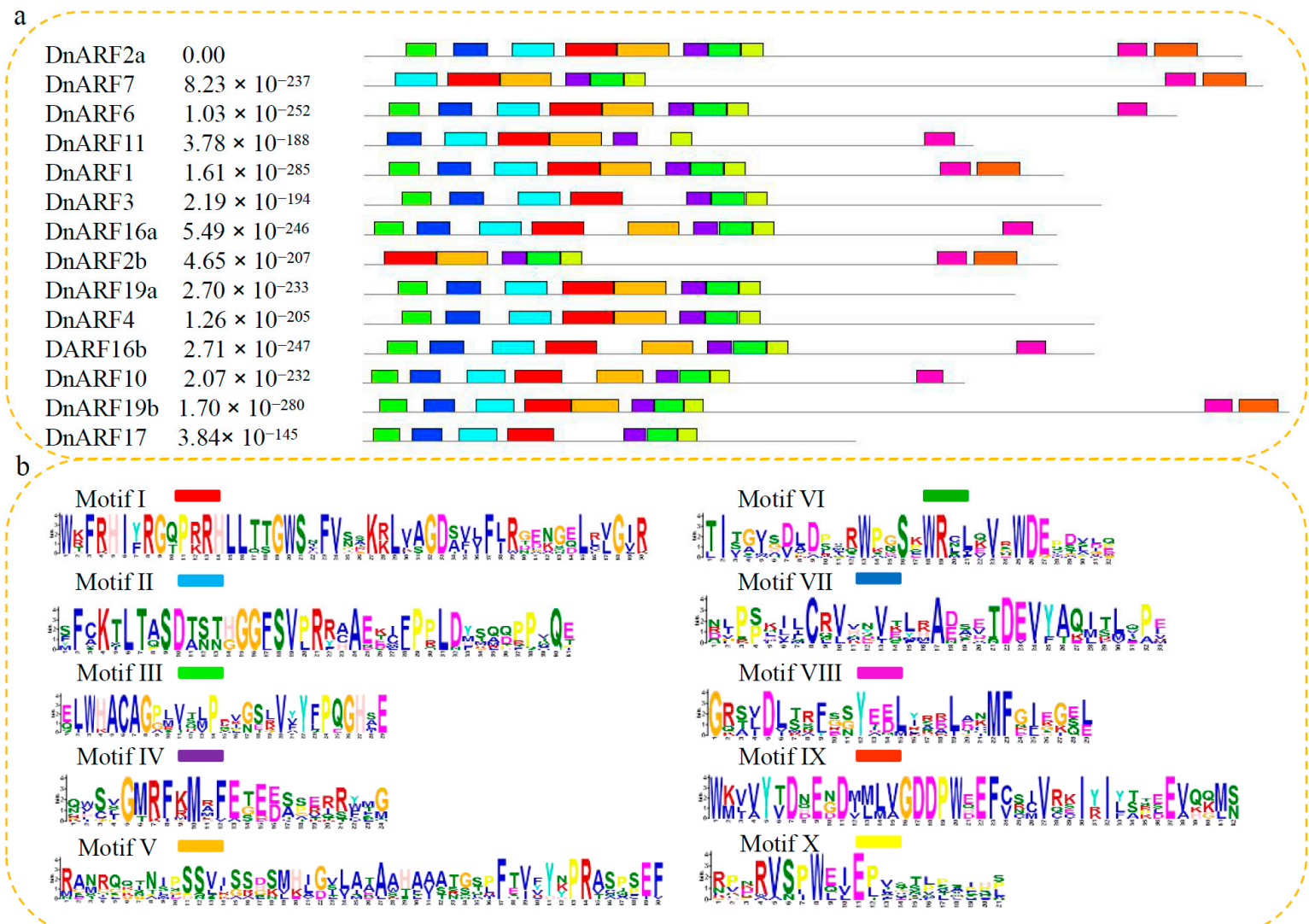

Figure 3. Analysis of motif distribution in DnARF proteins. Analysis of motif distribution in DnARF proteins. (a) Ten classical motifs in DnARF proteins were analyzed by MEME (Multiple Em for Motif Elicitation) online tool. The width of each motif ranged from six to 50 amino acids. Different color blocks represent different motifs. (b) Analysis of specific amino acid conservation in each motif. The height of each character represents different conservative degrees.

The amino acid compositions of the MRs and the classifications of the DnARFs were shown in Figure 4. The domain positions in the 14 DnARF proteins were listed in Table 1. The data showed that most of the DnARFs contained conserved DBDs, and variable MR and CTDs $[7,28]$. The 14 DnARFs can be divided into three classes based on the MR amino acid composition and the presence of CTDs. The DnARF family includes only two putative transcriptional activators, DnARF6 and 7, which contain an MR enriched in glutamine, serine, and leucine. This type of MR functions as an active domain in Arabidopsis or rice ARFs [7,33,34]. Most DnARFs, including DnARF1, 2a, 2b, 3, 6a, 6b, 9b, 10 and 11, are putative transcriptional repressors with MRs enriched in serine, leucine, proline, and glycine, similar to the Arabidopsis repressors [7,33]. DnARF4, 17and 19a do not contain a CTD. 


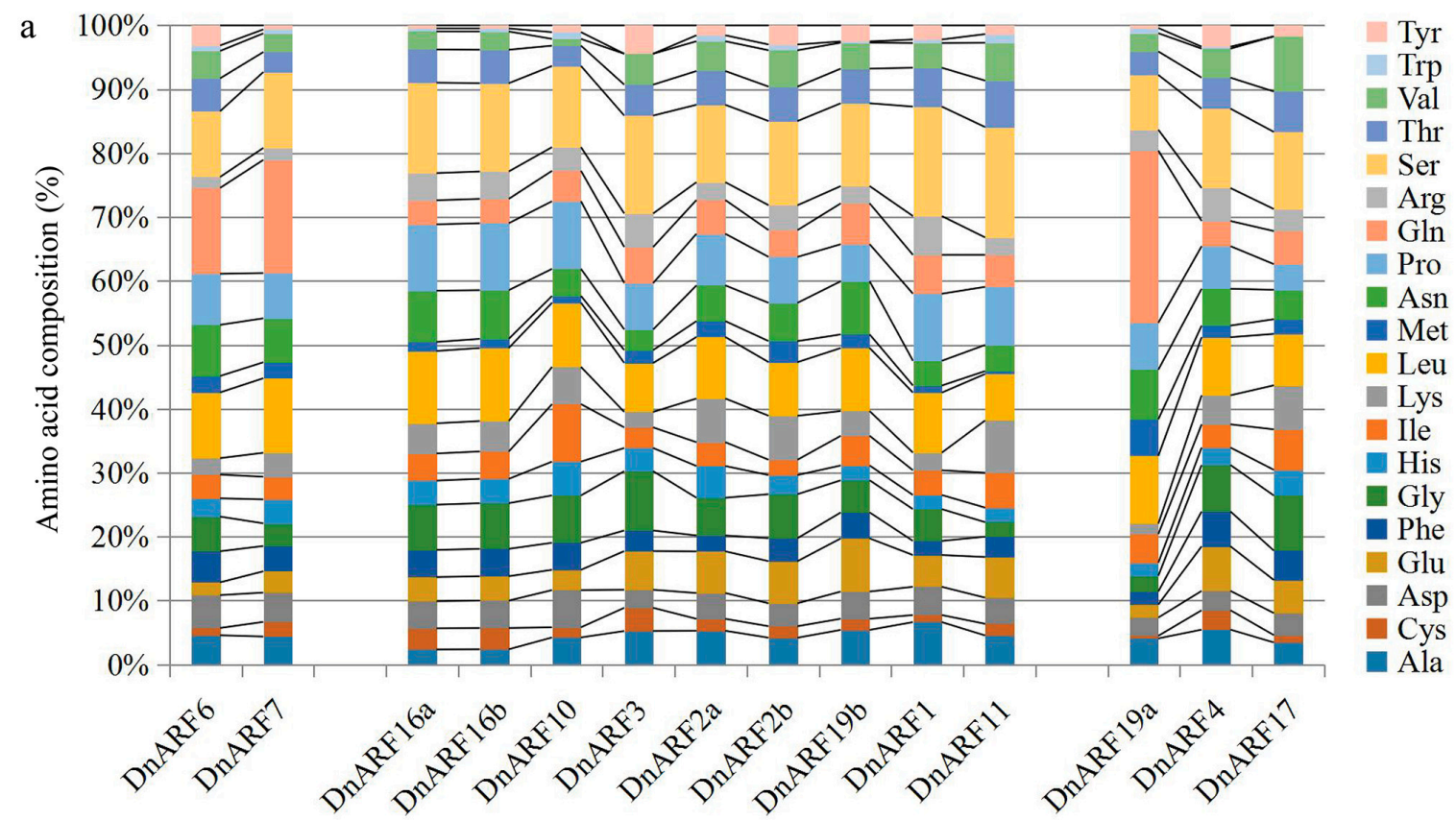

b

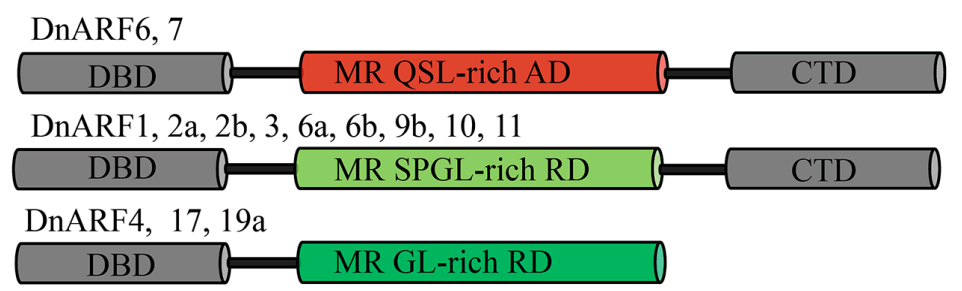

Figure 4. Analysis and classification of ARF family in D. officinale. (a) Amino acid compositions of the MR domains in various DnARF proteins. Different colors indicated different types of amino acids. (b) Classification of DnARF proteins based on their amino acid preferences and domain structures. DBD: B3 DNA-binding domain; MR: middle region; CTD: C-terminal dimerization domain; Q: glutamine; S: serine; L: leucine; G: glycine; P: proline; AD: activation domain; RD: repression domain.

\subsection{Subcellular Localization and Transcriptional Activation of Three Selected DnARFs}

Based on the results of the amino acid composition analysis, a transcription activator, DnARF6, a transcription repressor, DnARF1, and the CTD-truncated DnARF4 were selected for transcriptional activation tests. Firstly, the full-length ORFs of these three genes were fused in-frame to the $\mathrm{N}$ terminus of the GFP coding region. According to previous reports in other plant species, ARFs are nuclear-localized proteins [34]. We observed the transient expression of DnARF6, DnARF1, and DnARF4 in the epidermal cells of $N$. benthamiana leaves, confirming that they are nuclear proteins (Figure 5a).

To analyze the transcription activation capabilities of DnARF6, DnARF1, and DnARF4, autonomous activation tests were performed in the yeast system. On the SD medium lacking tryptophan, yeast strains containing one of the four constructs: empty BD, BD: DnARF6, BD: DnARF1, and BD: DnARF4, as well as a positive control, could grow well, indicating successful transformations. On the triple nutrient deficient SD medium, the strains containing the DnARF6 and the positive control could grow well; however, the strain with the empty BD, DnARF1, and DnARF4 did not survive (Figure 5b). Our data confirmed that DnARF6 may function as a transcriptional activator in D. officinale. 


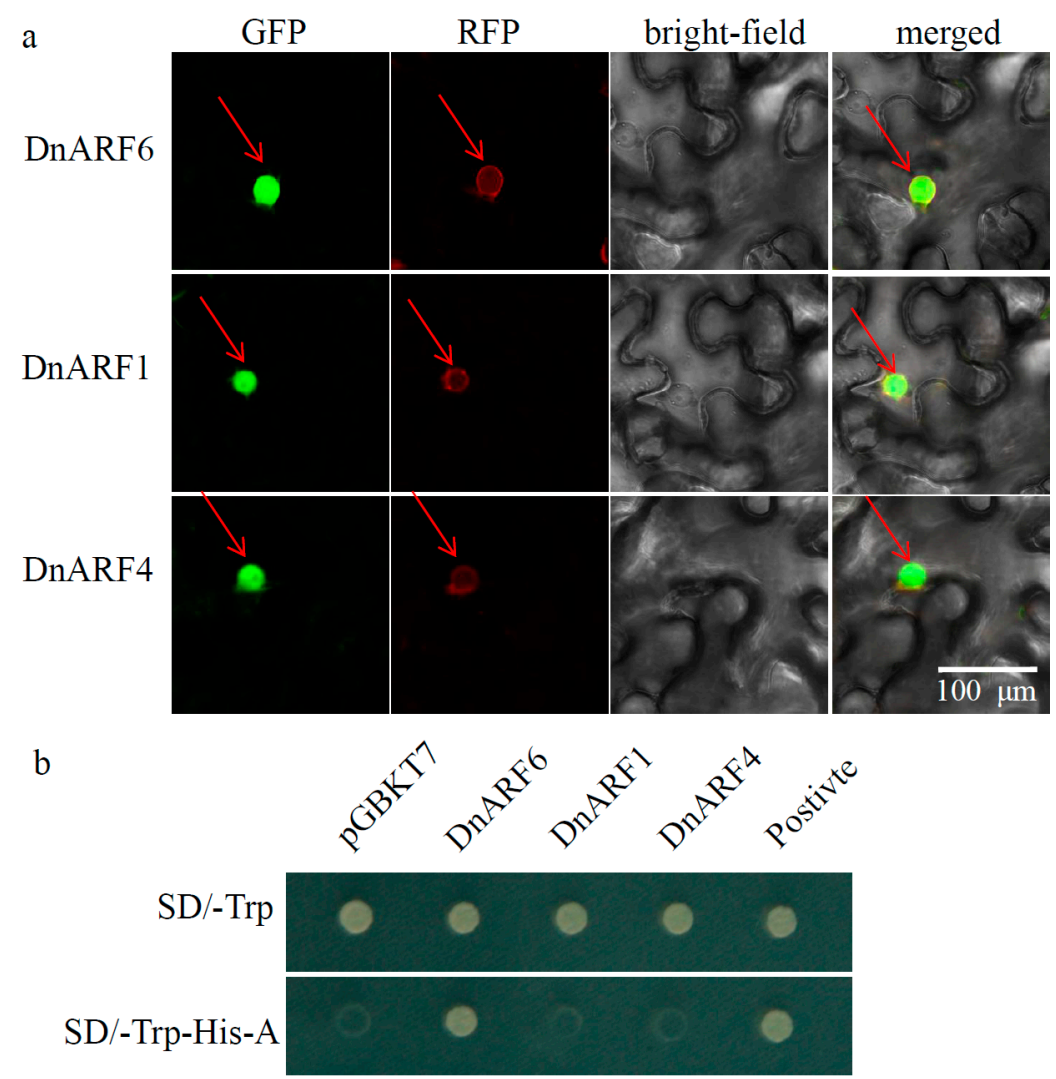

Figure 5. Subcellular localization and transcriptional activation of three selected DnARFs. (a) DnARF gene-GFP fusion constructs transiently expressed in tobacco epidermis cells. Localization of DnARF6, DnARF1, and DnARF4 fusion protein. Left to right: green fluorescence, red fluorescence, bright-field and merged. (b) Transcriptional activities of DnARF6, DnARF1, and DnARF4 were tested by the yeast system. The growth of transformed yeast strain AH109 with constructs under SD/-Trp and $\mathrm{SD} /$-Trp-His-A nutrition-deficient medium. BD refers to the pGBKT7 vector, which serves as the negative control.

\subsection{Expression Patterns for DnARF Genes in Different D. officinale Organs}

In our study, qRT-PCR was used to examine the spatial specificity of the expression patterns of each DnARF gene in different $D$. officinale organs. The transcript accumulations of these DnARF genes could be detected in at least one organ, and most of these genes expressed ubiquitously in all of the organs (Figure 6). The transcript levels of DnARF2b, DnARF17 and DnARF19b were hardly detectable in roots, suggesting their limited roles in root growth and development. DnARF6, DnARF10, DnARF17, DnARF19a and DnARF19b expressed much higher in the flowers than in other organs, and DnARF2a displayed the highest expression accumulation in the stems. DnARF11 had root-specific expression, indicating its role in root system establishment. 

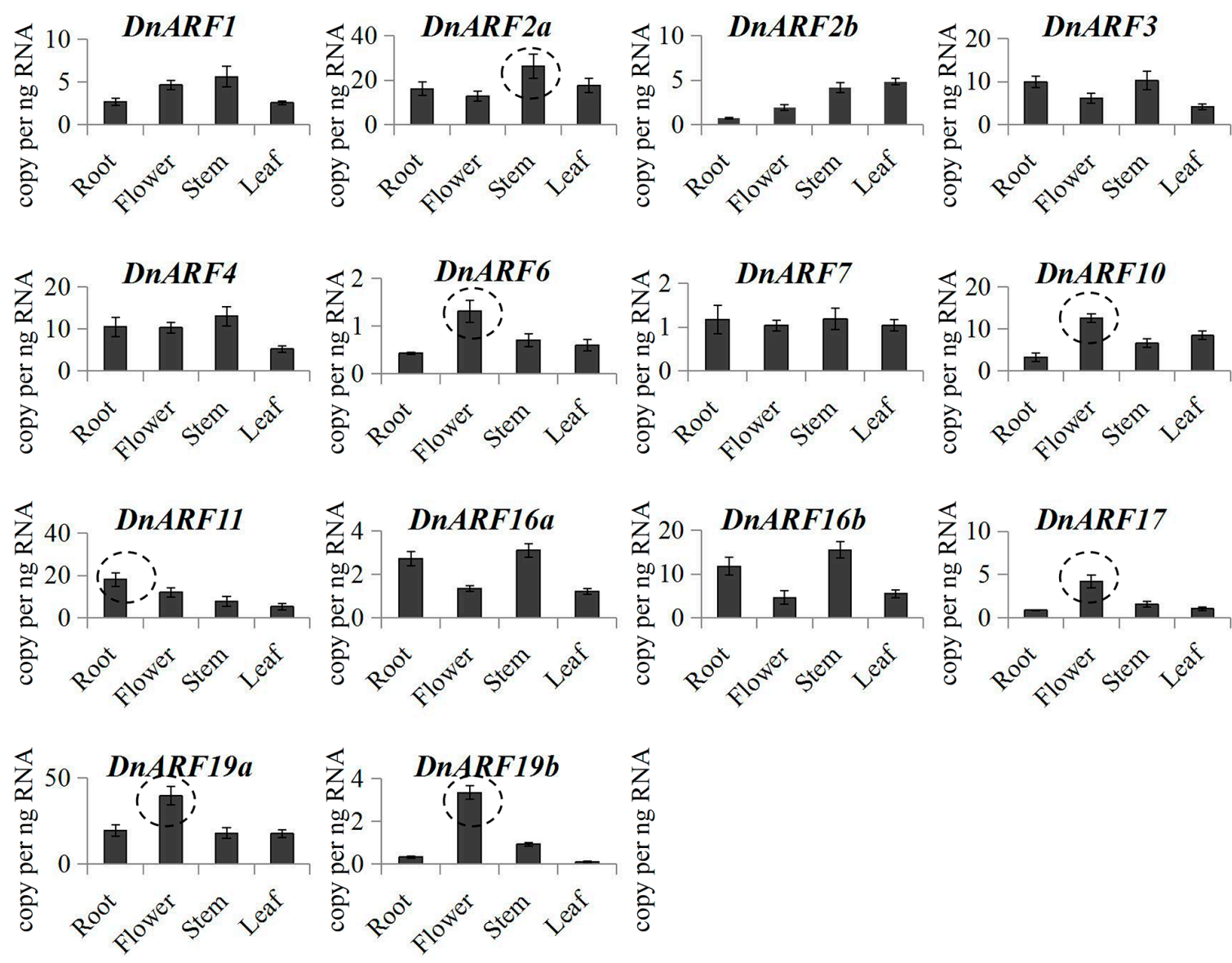

Figure 6. Organ-specific expression of DnARF family genes. Expression patterns of DnARF genes in four organs, including root, flower, stem, and leaf. The highest expression accumulation in organs was marked by dash line circles.

\subsection{Expression of DnARF Genes in Response to Various Hormone Treatments}

Previous study has revealed the involvement of hormones in plant responses to abiotic stresses [35]. In our study, the expression levels of the DnARF family genes in D. officinale seedlings were tested by qRT-PCR under Indole-3-acetic acid (IAA), abscisic acid (ABA), gibberellins (GA) and 6-Benzylaminopurine (6-BA) treatments, respectively. The expression levels of DnARF1, DnARF2a, DnARF2b, DnARF3, DnARF10, DnARF11, DnARF9a, and DnARF19b were significantly induced by the IAA treatment, and DnARF6 and DnARF17 were significantly reduced by the IAA treatment (Figure 7a). Under the ABA treatment, the expression levels of DnARF7, DnARF11, DnARF17, and DnARF19a were significantly up-regulated and the expression levels of DnARF3 and DnARF16b were significantly down-regulated (Figure 7b). Under the GA treatment, the expression levels of DnARF1, DnARF6, $D n A R F 7, D n A R F 19 a$, and DnARF19b were significantly up-regulated and the expression levels of DnARF4, DnARF16a, and DnARF16a were significantly down-regulated (Figure 7c). Under the 6-BA treatment, the expression levels of DnARF10, DnARF11, and DnARF19b were significantly induced and the expression levels of DnARF2a, DnARF3, and DnARF4 were significantly reduced (Figure 7d). The results suggested that the expression levels of some DnARF genes are responsive to these selected hormones. 

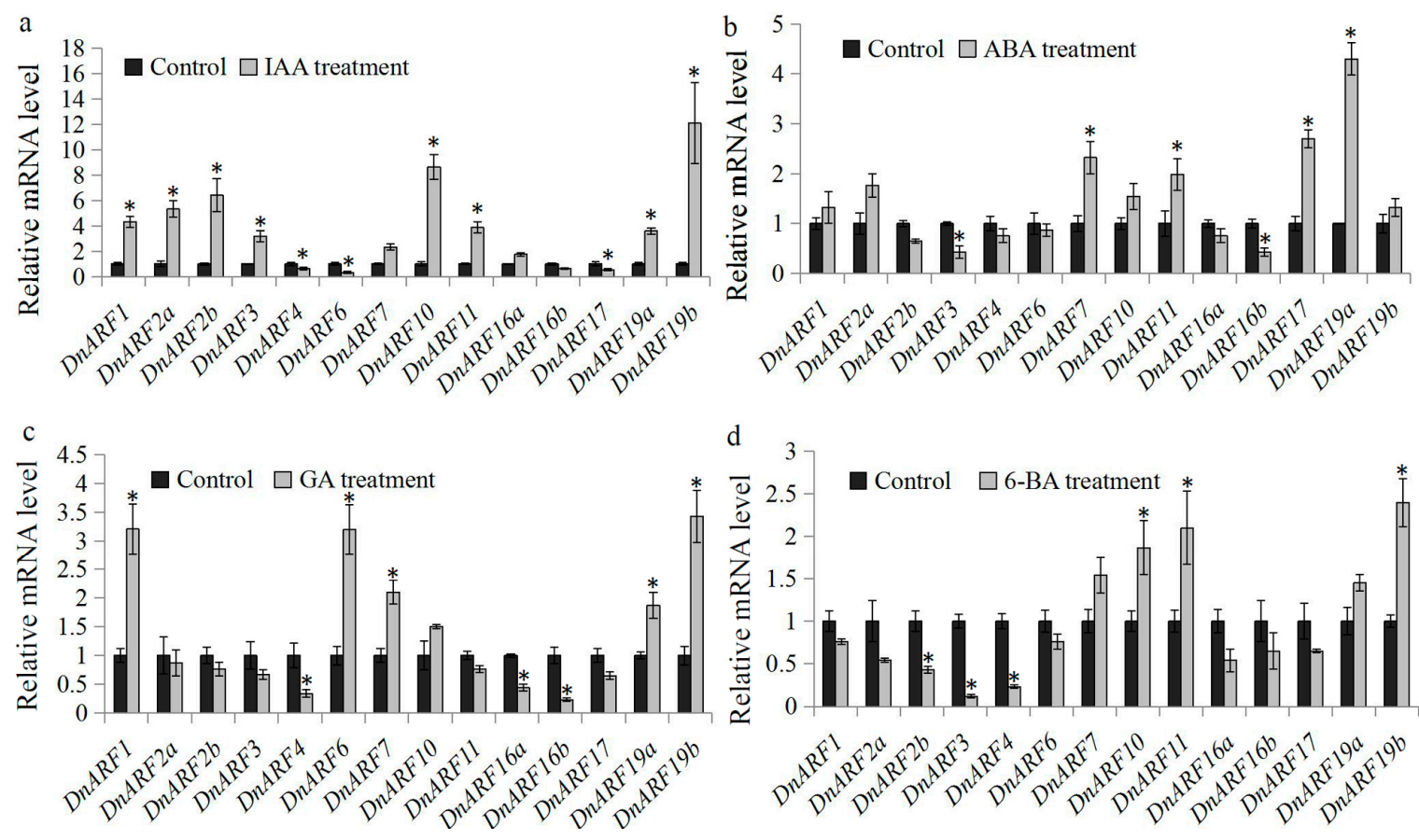

Figure 7. Expression analysis of $D n A R F$ genes under various hormone treatments. Total RNA was extracted from the seedlings of $D$. officinale for basal expression. The relative expression levels of 14 DnARF genes under (a) IAA, (b) ABA, (c) GA, and (d) 6-BA treatments. Significant differences in expression of DnARF genes between control and hormone treatments were indicated by '*'.

\subsection{Expression of DnARF Genes in Response to Various Abiotic Stress Treatments}

Abiotic stresses, including high salinity, dehydration, and extreme temperatures, are frequently experienced by plants under natural conditions [36,37]. Auxin controlled gene transcriptional regulation is an essential process required for plants to survive and adapt to adverse environmental challenges [21]. In our study, the expression patterns of DnARF genes under $\mathrm{NaCl}, \mathrm{PEG}$, and low $\left(4{ }^{\circ} \mathrm{C}\right)$ and high temperature $\left(30^{\circ} \mathrm{C}\right)$ treatments were analyzed to investigate their potential roles in $D$. officinale responses to various abiotic stresses.

Under the $\mathrm{NaCl}$ treatment, five DnARF genes, DnARF1, DnARF2a, DnARF7, DnARF10, and DnARF11, were significantly up-regulated, and only two genes, DnARF4 and DnARF6, were significantly down-regulated (Figure 8a). The expression levels of DnARF4, DnARF16a, DnARF17, and DnARF19a were significantly induced and the expression level of DnARF7 was significantly reduced by the PEG treatment (Figure 8b). Under the cold treatment, DnARF1, DnARF2a, and DnARF3 were significantly induced, and no significantly reduced $D n A R F$ genes were found (Figure 8c). The high temperature treatment significantly increased the expression levels of DnARF4, DnARF10, and DnARF17 and decreased the expression levels of DnARF2 $a$ and DnARF3 (Figure 8d). These results indicated that some $D n A R F$ genes are transcriptional responsive to abiotic stresses. 

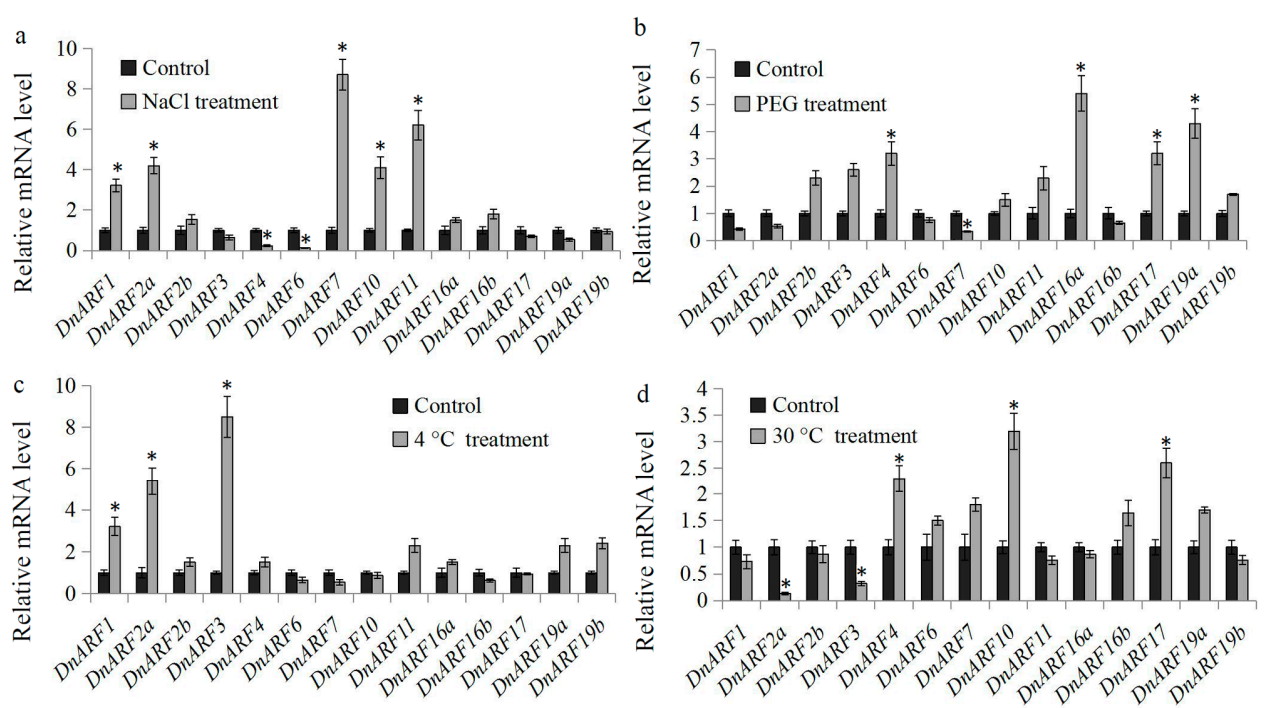

Figure 8. Expression analysis of $D n A R F$ genes under various abiotic treatments. Total RNA was extracted from the seedlings of $D$. officinale for basal expression. The relative expression levels of 14 DnARF genes under (a) $\mathrm{NaCl}$, (b) PEG, (c) $4{ }^{\circ} \mathrm{C}$, and (d) $30{ }^{\circ} \mathrm{C}$ treatments. Significant differences in expression of DnARF genes between control and abiotic treatments were indicated by "**".

\section{Discussion}

The phytohormone auxin is involved in regulating many aspects of plant growth and development [38-41]. ARF proteins form large and multigenic families in various plant species [18,19]. The isolation of $A R F$ gene families in plants aids in the understanding of their functions in growth and developmental processes [34,42]. The availability of sequence information in the public databases and transcriptomes in our laboratory allowed us to identify ARF family members in D. officinale. In this study, 14 Dendrobium ARFs were identified and their expression patterns were analyzed. Because the sequence lengths were limited to those of the transcriptomics unigenes, only $14 A R F$ genes with full-length coding sequences were identified in $D$. officinale, which is less than the numbers of $A R F$ family genes in other higher plants $[6,28,34]$. Considering the large size of the $D$. officinale genome, we believe that more ARFs exist in D. officinale [43]. For example, members of the subgroups $\mathrm{V}$ and VI were not identified in $D$. officinale, probably due to the incomplete sequence information from the transcriptome data (Figure 1).

A large number of $A R F s$ have been widely reported in many species. Our evolutionary analysis of DnARF genes with those from A. thaliana elucidated the conservation of ARF genes between D. officinale and the model plant. The subgroups I, II, III, and IV were conserved in the ARF genes of both D. officinale and Arabidopsis. All of the DnARF genes were distributed in four subgroups, I to IV which are homologous to AtARF1/2, AtARF3/4, AtARF5/6 and AtARF10/16, respectively (Figure 1). The evolutionary relationships of these genes between $D$. officinale and Arabidopsis suggested the putative biological functions of these newly identified ARFs [6,31,32].

In this study, all of the 14 DnARF proteins contained a B3-like DBD and an ARF domain (Figure 2). Three DnARF proteins; DnARF4, 17 and 19a, lacked a CTD, an important domain responsible for the interactions between ARFs and Auxin/IAAs (Figure 4b). The percentage of the CTD truncated DnARFs was $21.4 \%$, which was similar to that in sweet orange $(21.1 \%)$, tomato $(28.6 \%)$, rice $(25.0 \%)$ and Brassica rapa (22.6\%), and lower than that in papaya (36.4\%) and Medicago (58.3\%) [5,34,44,45]. This suggested that the gene expression regulation in D. officinale occurred in an auxin independent manner [30,46]. Many studies have verified that the transcriptional activities of ARFs depend on the amino acid composition of the MRs [28,34]. In our study, only two DnARF proteins; DnARF6 and DnARF7, were predicted as transcriptional activators, suggesting roles in the activation of the 
downstream target genes (Figure 4b). Furthermore, their transcriptional activation capabilities were confirmed by the yeast two-hybrid system (Figure 5b).

Hormones are involved in plant responses to changing environmental stimuli and stresses by affecting the expression levels of many ARF genes in different plant species [20,21]. However, the evaluation of various commercial hybrids and varieties of Dendrobium for suitability to the shifting surroundings is very limited. In our study, a systematic expression profile of the D. officinale ARF family genes under several hormones and different abiotic stresses was created.

The responsiveness to auxin treatments is a major feature of ARF genes in plants [28,47]. In D. officinale, 11 of the 14 DnARF genes showed significant changes in expression levels under IAA treatments compared with the control (Figure 7a). Our results are consistent with several previous reports on maize, cucumber and Medicago $[6,48,49]$. In addition to auxin, the role of the hormone cross-talk in response to abiotic stress has been uncovered [50]. In Arabidopsis, the stimulation of ABA signaling during seed dormancy is controlled by inducing ARF mediated ABI3 activation, which suggests a coordinating network of auxin and ABA signals [51]. For example, auxin acts upstream of ABI3 by recruiting the ARF10 and ARF16 to control the expression of ABI3 during seed germination [51]. Moreover, the transcriptional regulation of GA metabolism-related genes is also controlled by auxin signaling [52]. In tomato, SIARF7 mediates cross-talk between auxin and GA signaling during fruit set and development [53]. The differential expression of DnARF genes under ABA and GA treatments suggested the presence of hormone cross-talk in D. officinale (Figure $7 \mathrm{~b}, \mathrm{c}$ ). Recently, some abiotic stress-responsive $A R F$ genes have been reported in banana [22]. In sorghum, the expression levels of the SbARF10, 16, and 21 genes are significantly increased, over 10-fold, when subjected to a dehydration treatment [54]. In soybean seedlings, more than half of the ARF genes (33 in 51 GmARFs) are dehydration responsive in shoots and/or roots [20]. To our knowledge, there are few studies on the molecular mechanisms the environmental tolerance of D. officinale plants. Therefore, our data provided us many excellent candidates for further studies.

\section{Materials and Methods}

\subsection{Plant Material, Growth Conditions, and Treatments}

D. officinale seedlings were incubated in a greenhouse located at Hangzhou Normal University, Hangzhou, China. The three year old adult plants were transferred into independent pots and grown at a temperature of $25 \pm 1{ }^{\circ} \mathrm{C}$ with a light/dark cycle of $12 / 12 \mathrm{~h}$ and $60-70 \%$ relative humidity [55]. The leaf, stem, root, and flower samples were collected from the $D$. officinale plants during the flowering stage. There were three biological replicates for each organ. For hormone treatments, three year old plants were cultured in liquid half-strength Murashige and Skoog (MS) medium (Sigma-Aldrich, St. Louis, MO, USA), with $2 \%$ sucrose, at $\mathrm{pH} 5.4$ as controls. Plants were soaked in liquid half-strength MS supplemented with $10 \mu \mathrm{M}$ IAA, $100 \mu \mathrm{M}$ abscisic acid (ABA), $100 \mu \mathrm{M}$ gibberellic acid (GA), or $10 \mu \mathrm{M}$ 6-benzylaminopurine (6-BA) for 3 days. In the salt stress experiment, D. officinale plants were soaked in half-strength MS containing $150 \mathrm{mM} \mathrm{NaCl}$ for 3 days. In the dehydration stress experiment, $D$. officinale plants were treated with $20 \%$ polyethylene glycol (PEG) 6000 for 3 days. For the treatment, D. officinale plants were kept in greenhouse at a temperature of $4 \pm 1^{\circ} \mathrm{C}$ for 3 days. Untreated seedlings were used as controls.

\subsection{Isolation and Identification of ARF Genes in D. officinale Plants}

The partial sequences of the $A R F$ family genes were screened from four transcriptome data sets that were previously published [56]. All of the sequencing data sets are available at NCBI Sequence Read Archive (http:/ / www.ncbi.nlm.nih.gov/sra/) under accession IDs SRR2014227, SRR2014230, SRR2014236, SRR2014246, SRR2014297, SRR2014325, SRR2014396, and SRR2014476. All of the target unigenes were identified using the BLASTX algorithm, and sequences sharing more than $70 \%$ identity were assembled using SeqMan software in the Lasergene package. The 14 assembled sequences were analyzed and identified as full length cDNA sequences of $A R F$ genes in D. officinale. Furthermore, 
the hidden Markov model (HMM) profiles of the ARF protein family (Pfam 02309: AUX/IAA family; Pfam 06507: Auxin response factor (AUX_RESP), Pfam 02362: B3 DNA binding domain (B3) were employed to identify the $A R F$ genes from $D$. officinale. The sequences were sorted as unique sequences for a further protein domain search using InterProScan Sequence Search (http:/ /www.ebi.ac.uk/Tools/ $\mathrm{pfa} / \mathrm{iprscan} /$ ).

\subsection{Sequence Analysis, Phylogenetic Tree Building, and Prediction of Amino Acid Contents}

A multiple sequence alignment was performed for the DnARF protein sequences using ClustalW with the default parameters. Four classical domains, I, II, III, and IV, were identified in most of the DnARF proteins based on the alignments results. A phylogenetic tree was constructed with the 14 aligned DnARF protein sequences and 23 AtARF protein sequences using MEGA5.1 (http:/ /www. megasoftware.net/mega5/mega.html) employing the neighbor joining method. Bootstrap values were calculated from 1000 iterations. The Multiple Expectation Maximization for Motif Elicitation (MEME) web server (http://meme.nbcr.net/meme/cgi-bin/meme.cgi) was used to analyze motif distributions. Information on the ARF genes in Arabidopsis is listed in Table S1. The software MEGA 5.1 was also used to calculate the amino acid contents of the middle region (MR) domains in DnARF proteins. The classifications of DnARF proteins were based on the particular amino acid contents of the MRs. The activator domain, having a C-terminal domain (CTD), is glutamine/serine/leucine rich in the MR. The repressor domain having a CTD, is serine/proline/glycine/leucine rich in the MR, but the MR is glycine/leucine rich if there is no CTD.

\subsection{RNA Isolation and Quantitative RT-PCR}

Total RNA from different samples was extracted using a Plant RNeasy Mini kit (Qiagen, Hilden, Germany) according to the manufacturer's instructions. The gene DnActin (comp205612_c0) was used as an internal standard to calculate relative fold differences based on the comparative cycle threshold $\left(2^{-\Delta \Delta C t}\right)$ values. The procedure of qRT-PCR was as follows: one $\mu \mathrm{L}$ of a $1 / 10$ dilution of cDNA in $\mathrm{ddH}_{2} \mathrm{O}$ was add to five $\mu \mathrm{L}$ of $2 \times \mathrm{SYB}$ Green buffer, $0.1 \mu \mathrm{M}$ of each primer and $\mathrm{ddH}_{2} \mathrm{O}$ was then added to a final volume of $10 \mu \mathrm{L}$. The PCR conditions were $95^{\circ} \mathrm{C}$ for $10 \mathrm{~min}, 40$ cycles of $95^{\circ} \mathrm{C}$ for $15 \mathrm{~s}$ and $60{ }^{\circ} \mathrm{C}$ for $60 \mathrm{~s}$. All of the primer sequences are listed in Table S2. A histogram was constructed using the average values to visualize tissue specific expression levels.

Absolute quantification was used to calculate the tissue specific expression. The limit of detection and amplification efficiency of the qRT-PCR was carried out using 10-fold serial dilution of cDNA isolated from root sample, which was used to create a standard curve. Based on the standard curves, the slopes and correlation coefficients were used to calculate the PCR efficiency for each primer pairs. A formula: E = POWER (10,1/slope) -1 was used to calculate the PCR efficiency. Then, one $\mu \mathrm{L}$ cDNA (30 ng/ $\mu \mathrm{L}$ ) from different experiment samples were used as temples for qRT-PCR analysis. Based on the standard curve and PCR efficiency, threshold $\left(2^{-\Delta \Delta C t}\right)$ values were converted to copy per ng RNA.

\subsection{Subcellular Localization Analysis}

Full-length coding regions of two DnARF gene sequences were cloned into the vector pH7FWG2.0 to generate expression constructs. An artificial green fluorescent protein (GFP), fused in-frame to the $C$ terminus of each DnARF protein, was placed under the control of a cauliflower mosaic virus $35 \mathrm{~S}$ promoter. These constructs were transiently expressed in tobacco (Nicotiana benthamiana) epidermal cells using Agrobacterium mediated transformations. The fluorescence of the fusion protein constructs was detected using a confocal microscope LSM710 (Carl Zeiss, Oberkochen, Germany, http:/ / corporate. zeiss.com/) [57].

\subsection{Analysis of Transcriptional Activation}

The Matchmaker yeast two hybrid system (Clontech, Mountain View, CA, USA) was used to detect the transcriptional activation of DnARF6 and DnARF7. The deduced amino acid sequences of 
DnARF6 and DnARF7 were cloned and inserted into pGBKT7 in-frame fused with the GAL4 DBD to generate expression constructs. These constructs were transformed into yeast strain AH109 and selected on the minimal synthetic dextrose (SD) medium/-Trp and SD/-Trp-His-A to examine the reporter gene expression according to the Clontech Yeast Protocol Handbook. The interaction between the pGBKT7-p53 and pGADT7-SV40 large T-antigen was used as a positive control, and the empty pGBKT7 vector was used as a negative control.

\subsection{Statistical Analysis}

Differences between values were calculated using a one way analysis of variance with a Student's $t$-test at a significance level of 0.05 in Excel software (Microsoft, Seattle, WA, USA). All of the expression analyses were performed for five biological repeats, and the values shown in the figures represent the average values of five repeats. The data are expressed as the means and standard deviations (mean $\pm \mathrm{SD}$ ).

\section{Conclusions}

In conclusion, we have collected comprehensive information, such as basic parameters, conserved domains, the amino acid compositions, subcellular localizations, transcriptional activations, and expression patterns in different organs and under different abiotic treatments, on 14 identified DnARF genes in D. officinale. The responsiveness of the DnARF genes to various hormones and stresses suggests that DnARFs are involved in the D. officinale plants' tolerance to abiotic stresses.

Supplementary Materials: Supplementary materials can be found at www.mdpi.com/1422-0067/18/5/927/s1.

Acknowledgments: This work was supported by the National Natural Science Foundation of China (Grant No. 31100207 and 31401935), the Natural Science Foundation of Zhejiang Province, China (Grant No. LY14C020004 and LQ14C060001), and the Independent Agricultural Research Project of Hangzhou, China (Grant No. 20160432B03).

Author Contributions: Zhehao Chen and Yanjun Yang conceived and designed the research. Ye Yuan and Di Fu performed the experiments; Chenjia Shen analyzed the data; Zhehao Chen and Yanjun Yang contributed to writing the manuscript. All authors read and approved the final manuscript.

Conflicts of Interest: The authors declare no conflict of interest.

\section{Abbreviations}

$\begin{array}{ll}\text { ARF } & \text { Auxin response factor } \\ \text { Aux/IAA } & \text { Auxin/Indole-3-acetic acid } \\ \text { GH3 } & \text { Gretchen Hagen3 } \\ \text { SAUR } & \text { Small Auxin Up RNA } \\ \text { AuxREs } & \text { auxin response elements } \\ \text { DBD } & \text { DNA-binding domain } \\ \text { AD } & \text { activation domain } \\ \text { RD } & \text { repression domain } \\ \text { CTD } & \text { C-terminal dimerization domain } \\ \text { MS } & \text { Murashige and Skoog } \\ \text { ABA } & \text { abscisic acid } \\ \text { 6-BA } & \text { 6-benzylaminopurine } \\ \text { GA } & \text { gibberellic acid } \\ \text { PEG } & \text { polyethylene glycol } \\ \text { HMM } & \text { hidden Markov model } \\ \text { MEME } & \text { Multiple Expectation Maximization for Motif Elicitation } \\ \text { GFP } & \text { green fluorescent protein } \\ \text { ORF } & \text { open reading frame }\end{array}$




\section{References}

1. Ljung, K. Auxin metabolism and homeostasis during plant development. Development 2013, 140, 943-950. [CrossRef] [PubMed]

2. Tang, H.; Krishnakumar, V.; Bidwell, S.; Rosen, B.; Chan, A.; Zhou, S.; Gentzbittel, L.; Childs, K.L.; Yandell, M.; Gundlach, H.; et al. An improved genome release (version mt4.0) for the model legume Medicago truncatula. BMC Genom. 2014, 15, 312. [CrossRef]

3. Farzinebrahimi, R.; Taha, R.M.; Rashid, K.; Yaacob, J.S. The effect of various media and hormones via suspension culture on secondary metabolic activities of (Cape Jasmine) Gardenia jasminoides ellis. Sci. World J. 2014, 2014. [CrossRef] [PubMed]

4. Yue, R.; Tie, S.; Sun, T.; Zhang, L.; Yang, Y.; Qi, J.; Yan, S.; Han, X.; Wang, H.; Shen, C. Genome-wide identification and expression profiling analysis of ZmPIN, ZmPILS, ZmLAX and ZmABCB auxin transporter gene families in maize (Zea mays L.) under various abiotic stresses. PLoS ONE 2015, 10, e0118751. [CrossRef] [PubMed]

5. Shen, C.; Yue, R.; Yang, Y.; Zhang, L.; Sun, T.; Xu, L.; Tie, S.; Wang, H. Genome-wide identification and expression profiling analysis of the AUX/IAA gene family in Medicago truncatula during the early phase of sinorhizobium meliloti infection. PLoS ONE 2014, 9, e107495. [CrossRef] [PubMed]

6. Shen, C.; Yue, R.; Sun, T.; Zhang, L.; Xu, L.; Tie, S.; Wang, H.; Yang, Y. Genome-wide identification and expression analysis of auxin response factor gene family in Medicago truncatula. Front. Plant Sci. 2015, 6, 73. [CrossRef] [PubMed]

7. Ulmasov, T.; Hagen, G.; Guilfoyle, T.J. Activation and repression of transcription by auxin-response factors. Proc. Natl. Acad. Sci. USA 1999, 96, 5844-5849. [CrossRef] [PubMed]

8. Lim, P.O.; Lee, I.C.; Kim, J.; Kim, H.J.; Ryu, J.S.; Woo, H.R.; Nam, H.G. Auxin response factor 2 (ARF2) plays a major role in regulating auxin-mediated leaf longevity. J. Exp. Bot. 2010, 61, 1419-1430. [CrossRef] [PubMed]

9. Sessions, A.; Nemhauser, J.L.; McColl, A.; Roe, J.L.; Feldmann, K.A.; Zambryski, P.C. Ettin patterns the arabidopsis floral meristem and reproductive organs. Development 1997, 124, 4481-4491. [PubMed]

10. Hardtke, C.S.; Berleth, T. The arabidopsis gene monopteros encodes a transcription factor mediating embryo axis formation and vascular development. EMBO J. 1998, 17, 1405-1411. [CrossRef] [PubMed]

11. Harper, R.M.; Stowe-Evans, E.L.; Luesse, D.R.; Muto, H.; Tatematsu, K.; Watahiki, M.K.; Yamamoto, K.; Liscum, E. The NPH4 locus encodes the auxin response factor ARF7, a conditional regulator of differential growth in aerial Arabidopsis tissue. Plant Cell 2000, 12, 757-770. [CrossRef] [PubMed]

12. Goetz, M.; Vivian-Smith, A.; Johnson, S.D.; Koltunow, A.M. Auxin response factor8 is a negative regulator of fruit initiation in Arabidopsis. Plant Cell 2006, 18, 1873-1886. [CrossRef] [PubMed]

13. Ellis, C.M.; Nagpal, P.; Young, J.C.; Hagen, G.; Guilfoyle, T.J.; Reed, J.W. Auxin response factor 1 and auxin response factor 2 regulate senescence and floral organ abscission in Arabidopsis thaliana. Development 2005, 132, 4563-4574. [CrossRef] [PubMed]

14. Nagpal, P.; Ellis, C.M.; Weber, H.; Ploense, S.E.; Barkawi, L.S.; Guilfoyle, T.J.; Hagen, G.; Alonso, J.M.; Cohen, J.D.; Farmer, E.E.; et al. Auxin response factors ARF6 and ARF8 promote jasmonic acid production and flower maturation. Development 2005, 132, 4107-4118. [CrossRef] [PubMed]

15. Narise, T.; Kobayashi, K.; Baba, S.; Shimojima, M.; Masuda, S.; Fukaki, H.; Ohta, H. Involvement of auxin signaling mediated by IAA14 and ARF7/19 in membrane lipid remodeling during phosphate starvation. Plant Mol. Biol. 2010, 72, 533-544. [CrossRef] [PubMed]

16. Okushima, Y.; Fukaki, H.; Onoda, M.; Theologis, A.; Tasaka, M. ARF7 and ARF19 regulate lateral root formation via direct activation of LBD/ASL genes in Arabidopsis. Plant Cell 2007, 19, 118-130. [CrossRef] [PubMed]

17. Zouine, M.; Fu, Y.; Chateigner-Boutin, A.L.; Mila, I.; Frasse, P.; Wang, H.; Audran, C.; Roustan, J.P.; Bouzayen, M. Characterization of the tomato $A R F$ gene family uncovers a multi-levels post-transcriptional regulation including alternative splicing. PLoS ONE 2014, 9, e84203. [CrossRef] [PubMed]

18. Shen, C.; Yue, R.; Sun, T.; Zhang, L.; Yang, Y.; Wang, H. OsARF16, a transcription factor regulating auxin redistribution, is required for iron deficiency response in rice (Oryza sativa L.). Plant Sci. 2015, 231, 148-158. [CrossRef] [PubMed]

19. Shen, C.; Yue, R.; Yang, Y.; Zhang, L.; Sun, T.; Tie, S.; Wang, H. OsARF16 is involved in cytokinin-mediated inhibition of phosphate transport and phosphate signaling in rice (Oryza sativa L.). PLoS ONE 2014, 9, e112906. [CrossRef] [PubMed] 
20. Ha, C.V.; Le, D.T.; Nishiyama, R.; Watanabe, Y.; Sulieman, S.; Tran, U.T.; Mochida, K.; Dong, N.V.; Yamaguchi-Shinozaki, K.; Shinozaki, K.; et al. The auxin response factor transcription factor family in soybean: Genome-wide identification and expression analyses during development and water stress. DNA Res. 2013, 20, 511-524. [PubMed]

21. Xu, Y.X.; Mao, J.; Chen, W.; Qian, T.T.; Liu, S.C.; Hao, W.J.; Li, C.F.; Chen, L. Identification and expression profiling of the auxin response factors (ARFs) in the tea plant (Camellia sinensis (L.) O. Kuntze) under various abiotic stresses. Plant Physiol. Biochem. PPB Soc. Fr. Physiol. Veg. 2016, 98, 46-56. [CrossRef] [PubMed]

22. Hu, W.; Zuo, J.; Hou, X.; Yan, Y.; Wei, Y.; Liu, J.; Li, M.; Xu, B.; Jin, Z. The auxin response factor gene family in banana: Genome-wide identification and expression analyses during development, ripening, and abiotic stress. Front. Plant Sci. 2015, 6, 742. [CrossRef] [PubMed]

23. Lu, J.J.; Suo, N.N.; Hu, X.; Wang, S.; Liu, J.J.; Wang, H.Z. Development and characterization of 110 novel EST-SSR markers for Dendrobium officinale (orchidaceae). Am. J. Bot. 2012, 99, 415-420. [CrossRef] [PubMed]

24. Cheng, X.; Chen, W.; Zhou, Z.; Liu, J.; Wang, H. Functional characterization of a novel tropinone reductase-like gene in Dendrobium nobile Lindl. J. Plant Physiol. 2013, 170, 958-964. [CrossRef] [PubMed]

25. Juan, L.I.; Shunxiang, L.I.; Dan, H.; Zhao, X.; Cai, G. Advances in the of resources, constituents and pharmacological effects of Dendrobium officinale. Rev. Sci. Tech. 2011, 29, 74-79.

26. Wu, J.B.; Zhang, C.L.; Mao, P.P.; Qian, Y.S.; Wang, H.Z. First report of leaf spot caused by nigrospora oryzae on Dendrobium candidum in China. Plant Dis. 2014, 98, 996. [CrossRef]

27. Shen, C.; Guo, H.; Chen, H.; Shi, Y.; Meng, Y.; Lu, J.; Feng, S.; Wang, H. Identification and analysis of genes associated with the synthesis of bioactive constituents in Dendrobium officinale using RNA-Seq. Sci. Rep. 2017, 7, 187. [CrossRef] [PubMed]

28. Guilfoyle, T.J.; Hagen, G. Auxin response factors. Curr. Opin. Plant Biol. 2007, 10, 453-460. [CrossRef] [PubMed]

29. Liu, P.P.; Montgomery, T.A.; Fahlgren, N.; Kasschau, K.D.; Nonogaki, H.; Carrington, J.C. Repression of auxin response factor 10 by MicroRNA160 is critical for seed germination and post-germination stages. Plant J. 2007, 52, 133-146. [CrossRef] [PubMed]

30. Wang, D.; Pei, K.; Fu, Y.; Sun, Z.; Li, S.; Liu, H.; Tang, K.; Han, B.; Tao, Y. Genome-wide analysis of the auxin response factors $(A R F)$ gene family in rice (Oryza sativa). Gene 2007, 394, 13-24. [CrossRef] [PubMed]

31. Kalluri, U.C.; Difazio, S.P.; Brunner, A.M.; Tuskan, G.A. Genome-wide analysis of AUX/IAA and ARF gene families in Populus trichocarpa. BMC Plant Biol. 2007, 7, 59. [CrossRef] [PubMed]

32. Li, S.B.; OuYang, W.Z.; Hou, X.J.; Xie, L.L.; Hu, C.G.; Zhang, J.Z. Genome-wide identification, isolation and expression analysis of auxin response factor (ARF) gene family in sweet orange (Citrus sinensis). Front. Plant Sci. 2015, 6, 119. [CrossRef] [PubMed]

33. Tiwari, S.B.; Hagen, G.; Guilfoyle, T.J. AUX/IAA proteins contain a potent transcriptional repression domain. Plant Cell 2004, 16, 533-543. [CrossRef] [PubMed]

34. Shen, C.; Wang, S.; Bai, Y.; Wu, Y.; Zhang, S.; Chen, M.; Guilfoyle, T.J.; Wu, P.; Qi, Y. Functional analysis of the structural domain of ARF proteins in rice (Oryza sativa L.). J. Exp. Bot. 2010, 61, 3971-3981. [CrossRef] [PubMed]

35. Xiong, L.; Schumaker, K.S.; Zhu, J.K. Cell signaling during cold, drought, and salt stress. Plant Cell 2002, 14, S165-S183. [PubMed]

36. Jian, H.; Wang, J.; Wang, T.; Wei, L.; Li, J.; Liu, L. Identification of rapeseed micrornas involved in early stage seed germination under salt and drought stresses. Front. Plant Sci. 2016, 7, 658. [CrossRef] [PubMed]

37. Liu, S.C.; Xu, Y.X.; Ma, J.Q.; Wang, W.W.; Chen, W.; Huang, D.J.; Fang, J.; Li, X.J.; Chen, L. Small RNA and degradome profiling reveals important roles for MicroRNAs and their targets in tea plant response to drought stress. Physiol. Plant. 2016, 158, 435. [CrossRef] [PubMed]

38. Yang, X.; Liu, X.; Lv, W.; Li, L.; Shi, Q.; Yang, J.; Zhang, M. Reduced expression of bjrce1 gene modulated by nuclear-cytoplasmic incompatibility alters auxin response in cytoplasmic male-sterile Brassica juncea. PloS ONE 2012, 7, e38821. [CrossRef] [PubMed]

39. Liu, K.; Yue, R.; Yuan, C.; Liu, J.; Zhang, L.; Sun, T.; Yang, Y.; Tie, S.; Shen, C. Auxin signaling is involved in iron deficiency-induced photosynthetic inhibition and shoot growth defect in rice ( Oryza sativa L.). J. Plant Biol. 2015, 58, 391-401. [CrossRef]

40. Rondinini, S.; Confalonieri, C.; Longhi, P.; Mussini, T. The auxin transporter, OSAUX1, is involved in primary root and root hair elongation and in Cd stress responses in rice (Oryza sativa L.). Plant J. Cell Mol. Biol. 2015, 83,818 . 
41. Feng, S.; Yue, R.; Tao, S.; Yang, Y.; Zhang, L.; Xu, M.; Wang, H.; Shen, C. Genome-wide identification, expression analysis of auxin-responsive GH3 family genes in maize (Zea mays L.) under abiotic stresses. J. Integr. Plant Biol. 2015, 57, 783-795. [CrossRef] [PubMed]

42. Qi, Y.; Wang, S.; Shen, C.; Zhang, S.; Chen, Y.; Xu, Y.; Liu, Y.; Wu, Y.; Jiang, D. OsARF12, a transcription activator on auxin response gene, regulates root elongation and affects iron accumulation in rice (Oryza sativa). New Phytol. 2012, 193, 109-120. [CrossRef] [PubMed]

43. Yan, L.; Wang, X.; Liu, H.; Tian, Y.; Lian, J.; Yang, R.; Hao, S.; Wang, X.; Yang, S.; Li, Q.; et al. The genome of Dendrobium officinale illuminates the biology of the important traditional chinese orchid herb. Mol. Plant 2015, 8, 922-934. [CrossRef] [PubMed]

44. Wu, J.; Wang, F.; Cheng, L.; Kong, F.; Peng, Z.; Liu, S.; Yu, X.; Lu, G. Identification, isolation and expression analysis of auxin response factor (ARF) genes in Solanum lycopersicum. Plant Cell Rep. 2011, 30, 2059-2073. [CrossRef] [PubMed]

45. Liu, K.; Yuan, C.; Li, H.; Lin, W.; Yang, Y.; Shen, C.; Zheng, X. Genome-wide identification and characterization of auxin response factor $(A R F)$ family genes related to flower and fruit development in papaya (Carica papaya L.). BMC Genom. 2015, 16, 901. [CrossRef] [PubMed]

46. Kumar, R.; Tyagi, A.K.; Sharma, A.K. Genome-wide analysis of auxin response factor (ARF) gene family from tomato and analysis of their role in flower and fruit development. Mol. Genet. Genom. 2011, 285, 245-260. [CrossRef] [PubMed]

47. Hagen, G.; Guilfoyle, T. Auxin-responsive gene expression: Genes, promoters and regulatory factors. Plant Mol. Biol. 2002, 49, 373-385. [CrossRef] [PubMed]

48. Xing, H.; Pudake, R.N.; Guo, G.; Xing, G.; Hu, Z.; Zhang, Y.; Sun, Q.; Ni, Z. Genome-wide identification and expression profiling of auxin response factor $(A R F)$ gene family in maize. BMC Genom. 2011, 12, 178. [CrossRef] [PubMed]

49. Jian, W.; Liu, S.; Guan, X.; Chen, L.; He, Y.; Jie, W.; Gang, L. Genome-wide identification and transcriptional profiling analysis of auxin response-related gene families in cucumber. BMC Res. Notes 2014, 7, 1-13.

50. Popko, J.; Hansch, R.; Mendel, R.R.; Polle, A.; Teichmann, T. The role of abscisic acid and auxin in the response of poplar to abiotic stress. Plant Biol. 2010, 12, 242-258. [CrossRef] [PubMed]

51. Liu, X.; Zhang, H.; Zhao, Y.; Feng, Z.; Li, Q.; Yang, H.Q.; Luan, S.; Li, J.; He, Z.H. Auxin controls seed dormancy through stimulation of abscisic acid signaling by inducing ARF-mediated ABI3 activation in Arabidopsis. Proc. Natl. Acad. Sci. USA 2013, 110, 15485-15490. [CrossRef] [PubMed]

52. Frigerio, M.; Alabadi, D.; Perez-Gomez, J.; Garcia-Carcel, L.; Phillips, A.L.; Hedden, P.; Blazquez, M.A. Transcriptional regulation of gibberellin metabolism genes by auxin signaling in Arabidopsis. Plant Physiol. 2006, 142, 553-563. [CrossRef] [PubMed]

53. De, J.M.; Woltersarts, M.; Garcíamartínez, J.L.; Mariani, C.; Vriezen, W.H. The Solanum lycopersicum auxin response factor 7 (SIARF7) mediates cross-talk between auxin and gibberellin signalling during tomato fruit set and development. J. Exp. Bot. 2011, 62, 617.

54. Wang, S.; Bai, Y.; Shen, C.; Wu, Y.; Zhang, S.; Jiang, D.; Guilfoyle, T.J.; Chen, M.; Qi, Y. Auxin-related gene families in abiotic stress response in Sorghum bicolor. Funct. Integr. Genom. 2010, 10, 533-546. [CrossRef] [PubMed]

55. Shen, C.; Yang, Y.; Liu, K.; Zhang, L.; Guo, H.; Sun, T.; Wang, H. Involvement of endogenous salicylic acid in iron-deficiency responses in Arabidopsis. J. Exp. Bot. 2016, 67, 4179-4193. [CrossRef] [PubMed]

56. Meng, Y.; Yu, D.; Xue, J.; Lu, J.; Feng, S.; Shen, C.; Wang, H. A transcriptome-wide, organ-specific regulatory map of Dendrobium officinale, an important traditional chinese orchid herb. Sci. Rep. 2016, 6, 18864. [CrossRef] [PubMed]

57. Shen, C.; Yue, R.; Bai, Y.; Feng, R.; Sun, T.; Wang, X.; Yang, Y.; Tie, S.; Wang, H. Identification and analysis of Medicago truncatula auxin transporter gene families uncover their roles in responses to Sinorhizobium meliloti infection. Plant Cell Physiol. 2015, 56, 1930-1943. [CrossRef] [PubMed]

(C) 2017 by the authors. Licensee MDPI, Basel, Switzerland. This article is an open access article distributed under the terms and conditions of the Creative Commons Attribution (CC BY) license (http://creativecommons.org/licenses/by/4.0/). 